\title{
Delayed diagnosis of Addison's disease: an approach to management
}

\author{
Janice V Mascarenhas, Edward B Jude
}

Department of Diabetes and Endocrinology, Tameside Hospital NHS Foundation Trust Ashton under Lyne, Lancs, UK

\section{Correspondence to} Dr Edward B Jude, edward.jude@tgh.nhs.uk

Accepted 22 June 2014

\section{CrossMark}

To cite: Mascarenhas JV Jude EB. BMJ Case Rep Published online: [please include Day Month Year] doi:10.1136/bcr-2014204005

\section{SUMMARY}

Addison's disease accounts for the majority of cases of adrenal failure that are detected during hospital admissions. Unfortunately, prompt diagnosis of this condition is often delayed due to varied atypical manifestations and inadequate assessment at the time of presentation. We report a case of a 52-year-old woman who was detected to have hypotension during routine colonoscopy for evaluation of anaemia and progressive weight loss. During admission for evaluation of hypotension, she was also detected to have hyponatremia. Hyponatremia and hypotension failed to improve despite fluid resuscitation. Our endocrinological opinion was sought for and on further evaluation she was diagnosed with primary adrenal insufficiency. Glucocorticoid and mineralocorticoid replacement therapy were eventually instituted, which was followed by restoration of blood pressure and normalisation of serum sodium levels.

\section{BACKGROUND}

Addison's disease (AD) is a frequent cause of adrenal insufficiency which is multifactorial in origin. It may be primary (due to direct insult to the adrenal glands) or secondary (mostly resulting from a pituitary deficit). The annual incidence of $\mathrm{AD}$ in the western population is estimated to be around 4.7-6.2 per million people with a prevalence of 93-140 per million people in industrialised countries, which is mostly attributed to autoimmunity. ${ }^{1}$ In the $\mathrm{UK}, \mathrm{AD}$ affects around 1 in 10000 individuals with an estimate of around 8400 currently diagnosed cases. ${ }^{2}$ The majority of cases are unmasked following hospital admission as the patients initially manifest with vague features of fatigue, anorexia, weakness, abdominal pain and deranged electrolytes.

We report a case of $\mathrm{AD}$ to emphasise on the importance of early diagnosis and the benefits of prompt institution of medical management in such situations. This should serve as a guide for clinicians as the diagnosis of $\mathrm{AD}$ may be overlooked due to its obscure presentation and, deferred intervention can result in unnecessary complications and increased mortality.

\section{CASE PRESENTATION}

A 52-year-old woman presented to her general practitioner with a 2-month history of weight loss (of 2 stones) and constipation. There was no history of abdominal pain or bleeding per rectum. She had a history of bronchial asthma that was managed with albuterol. On examination, her weight was 8 stones $(50.8 \mathrm{~kg})$, and systemic examination was within normal limits. Routine haematological and biochemical assessment revealed the following parameters: haemoglobin $(\mathrm{Hb}) 12.4 \mathrm{~g} / \mathrm{dL}$, mean corpuscular volume (MCV) $87.3 \mathrm{fL}$, haematocrit (HCT) 37.4, red blood cell 4.29 million $/ \mathrm{mm}^{3}$, white cell count $7100 / \mathrm{mm}^{3}$, platelets $306000 / \mathrm{mm}^{3}$, erythrocyte sedimentation rate $8 \mathrm{~mm} / \mathrm{h}$ and ferritin $115 \mu \mathrm{g} / \mathrm{L}$, normal renal and liver function.

Five months later, she still reported continued weight loss despite a normal appetite (weight $48 \mathrm{~kg}$ ). A second haematological analysis revealed normocytic anaemia ( $\mathrm{Hb} 10.6 \mathrm{~g} / \mathrm{dL}$, HCT 31, MCV $86.5 \mathrm{fL})$. Owing to persistent weight loss and a recent diagnosis of anaemia, she was advised to undergo an elective colonoscopy (3 weeks later) to rule out a malignant cause. However, on the day of the scheduled colonoscopy, she was detected to have hypotension (supine blood pressure (BP) on two separate occasions: 70/50 and $63 / 38 \mathrm{~mm} \mathrm{Hg}$, with a heart rate of $93 \mathrm{bpm}$ ) and was hence admitted for fluid resuscitation. Following admission (day 1), she received $3 \mathrm{~L}$ of Hartmann's solution intravenously for hypotension and severe dehydration. On day 2, the patient was found to be delirious and was detected to have a random blood glucose of $1.6 \mathrm{mmol} / \mathrm{L}$; hypotension (BP 70/ $45 \mathrm{~mm} \mathrm{Hg}$ ) still persisted despite fluid resuscitation. Serum electrolytes were normal $\left(\mathrm{Na} 135 \mathrm{mmol} / \mathrm{L} ; \mathrm{K}^{+}\right.$ $4.2 \mathrm{mmol} / \mathrm{L}$ ). For this initial hypoglycaemic event, she received $100 \mathrm{~mL}$ of $10 \%$ dextrose and $1 \mathrm{~L}$ of $5 \%$ dextrose, $1 \mathrm{~h}$ following which the blood glucose normalised to $6.3 \mathrm{mmol} / \mathrm{L}$. Unfortunately, attempts to restore the BP failed despite adequate fluid resuscitation with $1 \mathrm{~L}$ of normal saline and $1 \mathrm{~L}$ of Hartmann's solution (BP 96/40). Subsequently, on day 3 , she was detected to have hyponatremia $(\mathrm{Na} 124 \mathrm{mmol} / \mathrm{L})$ which was treated with $1 \mathrm{~L}$ of normal saline. However, during the next 4 days her sodium levels began to deteriorate rapidly (initial serum $\mathrm{Na} 124 \mathrm{mmol} / \mathrm{L}$ which later dropped to $117 \mathrm{mmol} / \mathrm{L}$ ) in spite of daily fluid resuscitation with normal saline and Hartmann's solution. Additional diagnostic workup to determine the basis of hyponatremia included plasma osmolality $246 \mathrm{mOsm} / \mathrm{kg}$, urine osmolality $341 \mathrm{mOsm} / \mathrm{kg}$ and urinary $\mathrm{Na} 45 \mathrm{mmol} / \mathrm{L}$. With this unresolved background of persistent hyponatremia and hypotension, she was later referred to an endocrinologist at our hospital in order to expedite the course of treatment. As her clinical profile was suggestive of hypocortisolism (hypoglycaemia, hyponatremia and hypotension), a random cortisol was carried out, which was found to be very low $(26 \mathrm{nmol} / \mathrm{L})$. Consequently, a short Synacthen test (SST) was performed which revealed a baseline cortisol of $21 \mathrm{nmol} / \mathrm{L}$ and cortisol at $30 \mathrm{~min}$ was $88 \mathrm{nmol} / \mathrm{L}$. A diagnosis of $\mathrm{AD}$ was made as these levels are diagnostic of adrenal insufficiency (figure 1). 


\section{DIFFERENTIAL DIAGNOSIS}

The characteristic features of $\mathrm{AD}$ may be common to other medical conditions and must therefore be excluded. They include

- Hyponatemia: Seen in oedematous states (cardiac or liver disease); syndrome of inappropriate antidiuretic hormone secretion (dilutional hyponatremia).

- Weakness: Myopathies and neuropsychiatric disorders (anorexia nervosa).
- Hyperpigmentation: Bronchogenic carcinoma (ectopic adrenocorticotropin hormone (ACTH)), heavy metal poisoning, haemochromatosis, Peutz-Jegher syndrome.

- Hypoglycaemia: Insulinoma.

\section{TREATMENT}

Subsequent to the diagnosis of $\mathrm{AD}$, the patient was started on replacement therapy with intravenous hydrocortisone $(200 \mathrm{mg}$

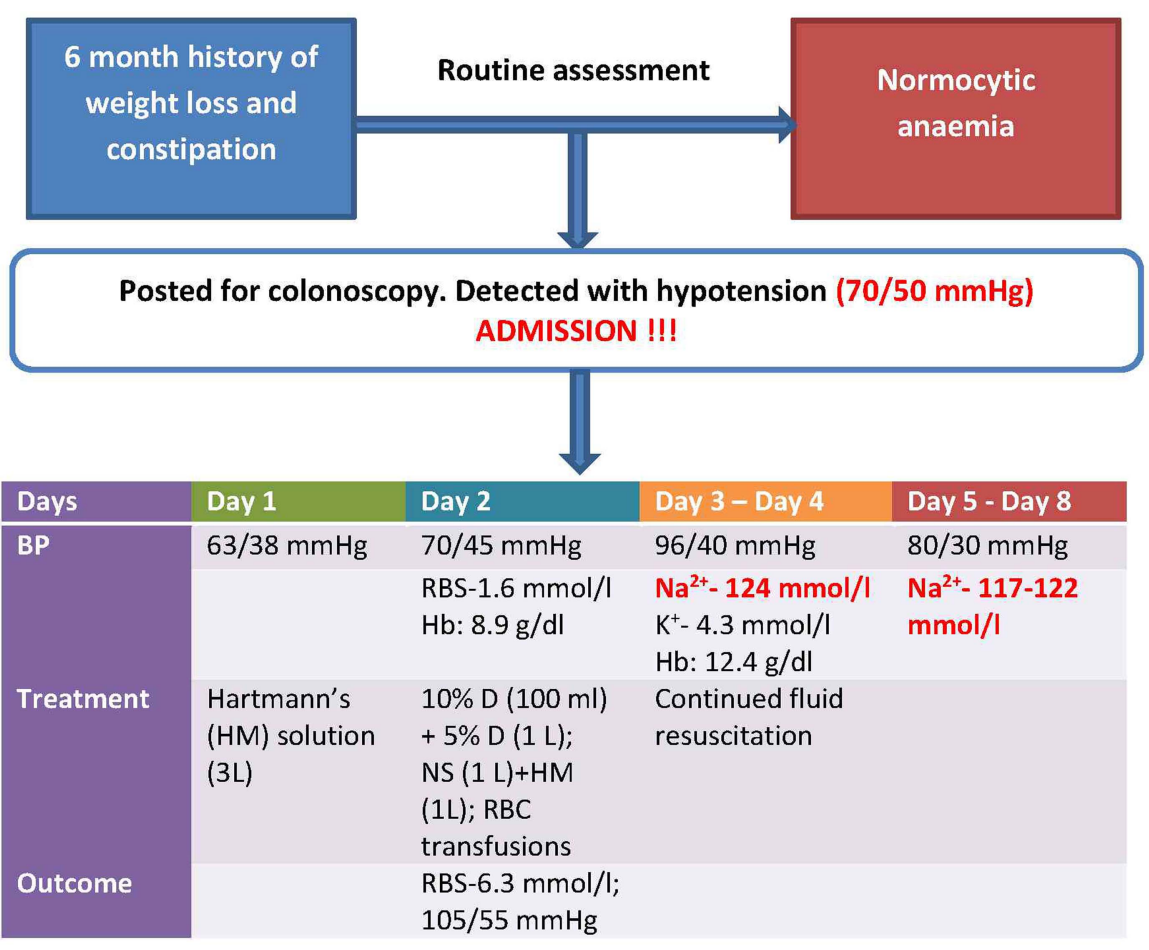

\section{Persistent hypotension and hyponatremia refractory to treatment}

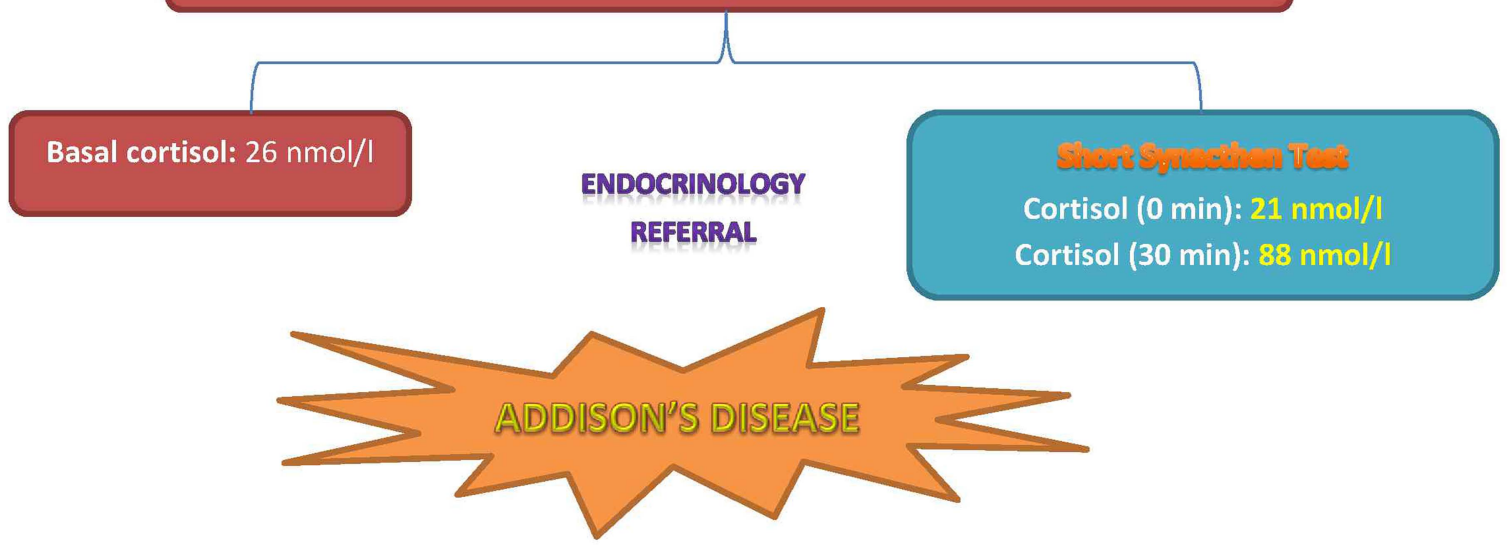

\begin{tabular}{|c|c|c|c|}
\hline Days & Day 8 & Day 9 & Day 10 - Day 16 \\
\hline & $\begin{array}{l}\text { Diagnosed with Addison's } \\
\text { disease }\end{array}$ & $\begin{array}{l}\mathrm{Na}^{2+}-130 \\
\text { BP: } 90 / 70 \mathrm{mmHg}\end{array}$ & $\mathrm{Na}^{2+}-133-143 \mathrm{mmol} / \mathrm{l}$ \\
\hline Treatment & $\begin{array}{l}\text { Hydrocortisone ( } 200 \mathrm{mg} \\
\text { stat+ } 100 \mathrm{mg} \text { every } 6 \mathrm{hrs} \text { ) } \\
\text { +background of saline } \\
\text { infusions }\end{array}$ & $\begin{array}{l}\text { Fludrocortisone }(100 \mu \mathrm{g}) \\
+\mathrm{HC} \text { infusions + NS }\end{array}$ & $\begin{array}{l}\text { Switched to oral therapy on } \\
\text { Day } 16 \text { and discharged: } \\
\mathrm{HC} 25 \mathrm{mg} \text { (10- } 10-5 \mathrm{mg})+ \\
\text { fludrocortisone } 100 \mu \mathrm{g} \\
\text { daily }\end{array}$ \\
\hline
\end{tabular}

Figure 1 Flow chart depicting the course of treatment of our patient in review. 
stat and then $100 \mathrm{mg}$ every $6 \mathrm{~h}$ ) and $100 \mu \mathrm{g}$ of fludrocortisone on a background of saline infusions. Following replacement therapy, hyponatremia and hypotension improved considerably and were restored to normal levels. CT of the adrenals revealed a normal study. At discharge, the patient was switched to oral maintenance therapy with hydrocortisone $25 \mathrm{mg}(10 \mathrm{mg}$ at $8: 00,10 \mathrm{mg}$ at 12:00 and $5 \mathrm{mg}$ at 17:00) and fludrocortisone $100 \mu \mathrm{g}$ daily. A repeat colonoscopy was performed (normal study) as the first one was unsuccessful due to an impassable sigmoid colon.

\section{OUTCOME AND FOLLOW-UP}

Presently the patient is being followed regularly at the endocrinology clinic and has repeatedly demonstrated adequate BP readings with restoration of serum electrolytes. Her thyroid function tests also reverted to normal after glucocorticoid replacement therapy. She has been able to regain her weight and is currently doing well.

\section{DISCUSSION}

$\mathrm{AD}$ or adrenal insufficiency may have an acute or chronic presentation. Acute adrenal insufficiency known as adrenal crisis or Addisonian crisis is a life-threatening medical emergency, which presents typically with destabilising haemodynamic parameters (circulatory collapse); it may be uncovered or precipitated by underlying stressors such as infections, trauma, surgery and other intercurrent illnesses. Under these circumstances, there is an increased metabolic demand for steroidogenesis to counteract the effect of these stressors. Patients may present with anorexia as the initial feature or may have frequent episodes of vomiting, abdominal pain, diarrhoea, fever and even hypoglycaemia. AD can also manifest chronically with atypical features of lethargy, weakness, weight loss, abdominal pain, vomiting, diarrhoea or constipation, depression and arthralgia. Hyperpigmentation (due to excessive ACTH stimulation of the melanocortin 1 receptor (MC1R)) is a typical feature of primary $\mathrm{AD}(94 \%$ of cases). ${ }^{3}$ Common sites involve the extensor surfaces, axillae, nipples, old scars, palmar creases, pressure points and mucous membranes. Patients with secondary AD experience symptoms of chronic adrenal insufficiency as well as those attributed to other hormonal deficits (due to hypopituitarism). Adrenal androgen deficiency is a feature of primary and secondary AD. In women, most of the androgen supply is derived from adrenal dehydroepiandrosterone (DHEA) production. Loss of pubic and axillary hair with loss of libido are features seen in women with $\mathrm{AD} .^{4}$

Common abnormalities in blood indices include anaemia, lymphocytosis and eosinophilia. ${ }^{5}$ Glucocorticoids are known to suppress TSH secretion. ${ }^{6}$ In $\mathrm{AD}$, it is not uncommon to encounter transient derangements in thyroid function parameters, which may also occur as part of the sick euthyroid syndrome that commonly accompanies intercurrent illnesses. These temporary alterations in thyroid function tend to normalise following glucocorticoid replacement therapy. Therefore, it is advisable not to initiate thyroxine supplementation in the face of deranged thyroid function tests (TFT) as elevated thyroxine levels hasten the metabolism of cortisol and can further perpetuate adrenal insufficiency. ${ }^{5}$

Hyponatremia is the most frequent electrolyte abnormality seen in AD. Eighty per cent of the acute cases have hyponatremia at presentation. Hyperkalemia is the second most common electrolyte abnormality observed $\left(50-60 \%\right.$ of cases). ${ }^{5}$ Hypercalcemia occurs in $6 \%$ of the cases and is evident in patients with coexistent thyrotoxicosis. ${ }^{7}$ As stated earlier, adrenal insufficiency may be primary or secondary in nature. Mineralocorticoid deficiency is apparent in primary AD and is depicted by elevated plasma renin activity in association with low or low-normal plasma aldosterone. On the contrary, the renin-angiotensin system is preserved in secondary AD.

Random serum cortisol levels can provide an indication of the adrenal status. A cortisol level $<100 \mathrm{nmol} / \mathrm{L}$ mandates urgent referral to an endocrinologist or hospital admission. Cortisol levels between 100 and $500 \mathrm{nmol} / \mathrm{L}$ warrant further assessment by an endocrinologist. Cortisol levels greater than $400 \mathrm{nmol} / \mathrm{L}$ usually indicate an intact hypothalamic-pituitaryadrenal (HPA) axis. ${ }^{8}$ The SST or ACTH stimulation test is a convenient and cost-effective procedure to diagnose $\mathrm{AD}$ as it can be carried out anytime during the day and on an outpatient basis. Adrenal reserve is estimated by measuring the serum cortisol levels at baseline and then at $30 \mathrm{~min}$ following an injection of $250 \mu \mathrm{g}$ of Synacthen (intravenous or intramuscular). Serum cortisol levels above $550 \mathrm{nmol} / \mathrm{L}(>20 \mu \mathrm{g} / \mathrm{dL})$ indicate a normal response. ${ }^{9}$ It should be borne in mind that the HPA axis should not be evaluated during an acute illness or infection as the cortisol levels tend to fluctuate in such situations. This is accounted for by the decrease in cortisol-binding globulin and simultaneous increase in free cortisol levels. In such cases, the adrenal reserve can be quantified by measurement of basal cortisol levels or by performance of SST. If required assessment of the HPA axis should be conducted after resolution of the underlying illness.

Since the majority of cases are autoimmune in origin, it would be wise to rule out other coexisting autoimmune diseases. Furthermore, adrenal antibodies can be detected in $75 \%$ of cases with autoimmune adrenalitis; adrenal autoantibody screening should be performed. ${ }^{10}$ Fifty per cent of these patients have an associated autoimmune disease which constitutes the autoimmune polyglandular syndromes (APS) - APS type I and II. APS type I or autoimmune polyendocrinopathy-candidiasis-ectodermal dysplasia consists of $\mathrm{AD}$, chronic mucocutaneous candidiasis and hypoparathyroidism. APS type II is comprised of AD, autoimmune thyroid disease, diabetes mellitus and hypogonadism.

Radiological imaging may facilitate screening for underlying focal infections. Chest X-ray may show evidence of tuberculosis (most common cause of $\mathrm{AD}$ in the developing world) or other infective pathology. ${ }^{11} \mathrm{CT}$ of the adrenals may reveal calcified or hyperplastic adrenals indicative of infection, haemorrhage or metastasis. MRI of the sella is warranted if the hormonal profile is suggestive of secondary $\mathrm{AD}$.

Acute $\mathrm{AD}$ is a medical emergency that necessitates immediate treatment pending further investigations. Glucocorticoid replacement preferably with intravenous hydrocortisone is initiated as a stat dose of $100 \mathrm{mg}$, followed by $100 \mathrm{mg}$ every $6 \mathrm{~h}$ during the first $24 \mathrm{~h}$. After this, the dose can be tapered to $50 \mathrm{mg}$ every $6 \mathrm{~h}$. If the patient is haemodynamically compromised then $1 \mathrm{~L}$ of saline infusion over $1 \mathrm{~h}$ should be instituted; dextrose infusions may be required in the presence of hypoglycaemic episodes. Mineralocorticoid therapy is provided only in primary $\mathrm{AD}$ if the hydrocortisone dose is less than $50 \mathrm{mg} /$ day. The daily dose ranges between 50 and $200 \mu \mathrm{g}$ /day given orally. Haemodynamic parameters and electrolytes should be monitored during mineralocorticoid replacement therapy. DHEA replacement is not required in acute $\mathrm{AD}$. Once the patient has stabilised, the management is similar to that of chronic AD. The objective of long-term replacement therapy or maintenance therapy with hydrocortisone is to simulate the physiological rate of cortisol secretion. Ideally short-acting glucocorticoids like hydrocortisone are desirable as synthetic glucocorticoids like 
prednisolone and dexamethasone have long biological half-lives that can bear a negative influence on bone mineral density and glucose tolerance. On the basis of the normal cortisol production rates of $8-15 \mathrm{mg} /$ day, this should equate to $15-25 \mathrm{mg} /$ day of hydrocortisone. The daily replacement dose can be divided into two to three doses per day with half the dose (larger dose) taken on awakening and a smaller dose later during the day. These requirements may be lower in secondary $\mathrm{AD}$ associated with growth hormone deficiency (insulin growth factor-1 increases cortisol clearance). Mineralocorticoid replacement with oral fludrocortisone $100 \mu \mathrm{g} /$ day should be continued in primary AD. DHEA replacement is primarily indicated in women with signs of androgen deficiency as it has been shown to improve well-being and mood. Twenty-five to $50 \mathrm{mg}$ of DHEA is taken as an oral dose in the morning. ${ }^{12}$

All patients with $\mathrm{AD}$ should receive education about stressrelated glucocorticoid dose adjustment, that is aimed at the prevention of future risks of adrenal crisis. Most of the crises are due to inadequate glucocorticoid replacement or inappropriate adjustment of glucocorticoid therapy during stressful events. They should be provided with medical-alert bracelets/cards. In the event of an acute illness, the dose of hydrocortisone should be doubled.

\section{Learning points}

- The varied and atypical manifestations of Addison's disease (AD) mandate a high index of suspicion in such cases in order to initiate treatment at the earliest.

- Evaluation of the hypothalamic-pituitary-adrenal axis should be considered only after resolution of an acute underlying illness. The short Synacthen test proves to be a valuable diagnostic tool under such circumstances.

- Patients diagnosed with $A D$ should continue to receive replacement with glucocorticoid and mineralocorticoid therapy to meet physiological requirements and prevent future adrenal crisis. This must be accompanied by frequent assessments of haemodynamic parameters and serum electrolytes.
For surgery, delivery or trauma, $100 \mathrm{mg}$ of hydrocortisone is given intravenously in $24 \mathrm{~h}$ or $25-50 \mathrm{mg}$ is given four times a day. Emergency hydrocortisone self-injection kits should be provided to patients who reside in remote areas; these kits prove vital even in scenarios where the patient is not able to ingest hydrocortisone orally (vomiting, gastrointestinal infections).

Contributors EBJ was involved in the management of the case in review. He chose to prepare this case report in order to enlighten practicing clinicians about the nature of Addison's disease and the importance of prompt diagnosis and management in such cases. JVM analysed the case records of the patient and drafted the case report which was reviewed by EBJ.

\section{Competing interests None.}

Patient consent Obtained.

Provenance and peer review Not commissioned; externally peer reviewed.

\section{REFERENCES}

1 Vaidya B, Chakera AJ, Dick C. Addison's disease. BMJ 2009;339:b2385.

2 Wass J, Howlett T, Arlt W, et al. Diagnosing Addison's: a guide for GPs. Addison's Disease Self Help Group, 2009.

3 Stewart PM, Krone NP. The adrenal cortex. Williams's textbook of endocrinology. 12th edn. Philadelphia: Elsevier, 2011:517-18.

4 Arlt W, Justl HG, Callies F, et al. Oral dehydroepiandrosterone for adrenal androgen replacement: pharmacokinetics and peripheral conversion to androgens and estrogens in young healthy females after dexamethasone suppression. J Clin Endocrinol Metab 1998:83:1928-34.

5 Arlt W. The approach to the adult with newly diagnosed adrenal insufficiency. J Clin Endocrinol Metab 2009;94:1059-67.

6 Hangaard J, Andersen M, Grodum E, et al. Pulsatile thyrotropin secretion in patients with Addison's disease during variable glucocorticoid therapy. J Clin Endocrinol Metab 1996:81:2502-7.

7 Muls E, Bouillon R, Boelaert J, et al. Etiology of hypercalcemia in a patient with Addison's disease. Calcif Tissue Int 1982:34:523-6.

8 Hagg E, Asplund K, Lithner F. Value of basal plasma cortisol assays in the assessment of pituitary-adrenal insufficiency. Clin Endocrinol (Oxf) $1987 ; 26: 221-6$

9 Clark PM, Neylon I, Raggatt PR, et al. Defining the normal cortisol response to the short Synacthen test: implications for the investigation of hypothalamic-pituitary disorders. Clin Endocrinol (Oxf) 1998;49:287-92.

10 Betterle C, Dal Pra C, Mantero F, et al. Autoimmune adrenal insufficiency and autoimmune polyendocrine syndromes: autoantibodies, autoantigens, and their applicability in diagnosis and disease prediction. Endocr Rev 2002;23:327-64.

11 Kelestimur F. The endocrinology of adrenal tuberculosis: the effects of tuberculosis on the hypothalamo-pituitary-adrenocortical function. J Endocrinol Invest 2004; $27: 380-6$

12 Arlt W, Callies F, van Vlijmen JC, et al. Dehydroepiandrosterone replacement in women with adrenal insufficiency. N Engl J Med 1999;341:1013-20.

Copyright 2014 BMJ Publishing Group. All rights reserved. For permission to reuse any of this content visit

http://group.bmj.com/group/rights-licensing/permissions.

BMJ Case Report Fellows may re-use this article for personal use and teaching without any further permission.

Become a Fellow of BMJ Case Reports today and you can:

- Submit as many cases as you like

- Enjoy fast sympathetic peer review and rapid publication of accepted articles

- Access all the published articles

- Re-use any of the published material for personal use and teaching without further permission

For information on Institutional Fellowships contact consortiasales@bmjgroup.com

Visit casereports.bmj.com for more articles like this and to become a Fellow 